\title{
Visfatin Promotes Monocyte Adhesion by Upregulating ICAM-1 and VCAM-1 Expression in Endothelial Cells via Activation of p38-PI3K-Akt Signaling and Subsequent ROS Production and IKK/NF-KB Activation
}

\author{
Yu-Ting Lin ${ }^{a}$ Luen-Kui Chen ${ }^{a}$ Deng-Yuan Jian ${ }^{a, b}$ Ting-Chia Hsu \\ Wei-Chih Huang ${ }^{a}$ Tse-Ting Kuan ${ }^{a}$ Shao-Yun Wu Ching-Fai Kwok ${ }^{\text {c,d }}$ \\ Low-Tone Ho ${ }^{\mathrm{a}, \mathrm{c}, \mathrm{d}}$ Chi-Chang Juan ${ }^{\mathrm{a}, \mathrm{d}, \mathrm{e}}$
}

\begin{abstract}
aInstitute of Physiology, School of Medicine, National Yang-Ming University, Taipei, Taiwan, 'Division of Nephrology, Wen-Lin Hemodialysis Unit, Taipei Veterans General Hospital, Taipei, Taiwan, 'Division of Endocrinology and Metabolism, Department of Internal Medicine, Taipei Veterans General Hospital, Taipei, Taiwan, 'Department of Medical Research, Taipei Veterans General Hospital, Taipei, Taiwan, eDepartment of Education and Research, Taipei City Hospital, Taipei, Taiwan
\end{abstract}

\section{Key Words}

Endothelial cell $\bullet$ ICAM-1 • Monocyte adhesion $\cdot$ VCAM-1 $・$ Visfatin

\begin{abstract}
Background/Aims: Visfatin is known to act as a mediator in several metabolic disorders, such as obesity, diabetes, and cardiovascular diseases. This study aimed to investigate the effect of visfatin on the adhesion of THP-1 monocytes to human vascular endothelial cells and the underlying mechanism. Methods: Monocytes adhesion to endothelial cells was determined by using fluorescence-labeled monocytes. ICAM- 1 and VCAM- 1 expression in endothelial cells were measured by western blotting. Production of reactive oxygen species (ROS) was measured by using a fluorescent dye. The amounts of nuclear factor-kappa $B$ (NF-KB) and phosphorylation of inhibitory factor of NF-KB (IKB) were determined by using western blot analysis. The translocation of NF-KB from the cytoplasm to the nucleus was determined by using immunofluorescence. Results: Here we showed that visfatin significantly caused the upregulation of intercellular cell adhesion molecule-1 (ICAM-1) and vascular cell adhesion molecule-1 (VCAM-1) in endothelial cells, as well as enhanced monocyte adhesion to endothelial cells. Moreover, we found that inhibition of PI3K, Akt, and p38 MAPK activation

Y.-T. Lin and L.-K. Chen contributed equally to this work.

\begin{tabular}{ll}
\hline Chi-Chang Juan, Ph.D. & Institute of Physiology, School of Medicine, National Yang-Ming University \\
& No. 155, Sec. 2, Li-Nong St., Taipei (Taiwan) \\
& Tel. (886)-2-28267085, Fax (886)-2-28264049, E-Mail ccjuan@ym.edu.tw
\end{tabular}
\end{abstract}




\section{Cellular Physiology Cell Physiol Biochem 2019;52:1398-1411 \\ \begin{tabular}{ll|l} 
and Biochemistry $\begin{array}{l}\text { DOl: 10.3594/0000000098 } \\
\text { Published online: 11 May 2019 }\end{array}$ & $\begin{array}{l}\text { O } 2019 \text { The Author(s). Published by } \\
\text { Cell Physiol Biochem Press GmbH\&Co. KG }\end{array}$ \\
\cline { 2 - 3 } &
\end{tabular} \\ Lin et al.: Visfatin Promotes Monocyte Adhesion and Its Signaling Pathway}

significantly prevented visfatin-enhanced expression of ICAM-1 and VCAM-1 and monocyte adhesion to endothelial cells. Visfatin enhanced ROS production and IKK/NF-KB activation and then led to upregulation of ICAM-1 and VCAM-1 and enhanced monocyte adhesion to endothelial cells. These effects were also p38/PI3K/Akt-dependent. Conclusion: These results demonstrated that visfatin promoted monocyte-endothelial cell adhesion by increasing ICAM- 1 and VCAM- 1 expression via the activation of p38/PI3K/Akt signaling and downstream ROS production and IKK/NF-KB activation.

(C) 2019 The Author(s). Published by Cell Physiol Biochem Press GmbH\&Co. KG

\section{Introduction}

Visfatin is an adipocytokine that is predominantly expressed and produced in visceral fat [1]. Fukuhara et al. demonstrated that visfatin exerts some insulin-mimetic effects, such as enhancing glucose uptake and inhibiting hepatocyte glucose release [2]. Besides, visfatin was also found to have important proinflammatory and immunomodulating properties [3]. Adipocytokines are viewed as a link between a possible mechanism in obesity-associated insulin resistance and cardiovascular diseases. Compared with normal controls, plasma levels of visfatin are significantly elevated in patients with obesity and/or type 2 diabetes mellitus [4-7]. In type 2 diabetic rats, plasma visfatin levels significantly increase and are positively correlated with body weight, fasting plasma glucose, and microalbuminuria [8]. Visfatin has also been shown to be produced by immune cells, such as neutrophils and macrophages [9-10]. A study demonstrated that plasma visfatin concentrations and mRNA expression in human peripheral blood cells were increased in obese patients, and high circulating visfatin levels are associated with inflammation, abnormal lipid metabolism, and fatty liver [11]. Another study also showed that visfatin elevates the secretion of cytokines TNF- $\alpha$, IL-1 $\beta$, and IL-6 in human leukocytes [12]. These observations highly implied that visfatin may play a crucial role in the pathogenesis of obesity-associated inflammation.

Visfatin is associated with various metabolic disorders [4-6], but investigations on the possible role of visfatin in the pathogenesis of cardiovascular complications are limited. Kim et al. demonstrated that visfatin upregulates the expression of ICAM-1 and VCAM-1 in human microvascular endothelial cells via reactive oxygen species (ROS)-dependent nuclear transcription factor NF-кB activation [13]. Lee et al. demonstrated that visfatin causes significant increases in IL-6, IL-8, ICAM-1, VCAM-1, and E-selectin expression and NF-кB activation in primary human umbilical vein endothelial cells (HUVECs) [14]. Furthermore, visfatin increases production of MCP-1 and IL- 6 through the p38 MAPK, PI3K, and ERK1/2 pathways in HUVECs [15]. These observations suggested that visfatin may be involved in the pathogenesis of vascular endothelial dysfunction, and the signaling pathways mediating visfatin actions remain controversial.

Monocyte-endothelial adhesion is one of the key events in the pathogenesis of atherosclerosis. The expression of adhesion molecules is partially responsible for cell adhesion of circulating monocytes to endothelial cells, which is the early stage of atherosclerosis. In the present study, we demonstrated that visfatin stimulated ICAM- 1 and VCAM- 1 expression and monocyte adhesion to endothelial cells in time- and dose-dependent manners. These visfatin actions were conducted by activating p38/PI3K/Akt signaling and subsequent ROS production and IKK/NF-KB activation.

\section{Materials and Methods}

\section{Materials}

The human vascular endothelial cell line EA.hy926 and monocytic cell line THP-1 were purchased from American Type Culture Collection (ATCC) (Manassas, VA, USA). Dulbecco's Modified Eagle Medium (DMEM), RPMI 1640 medium, fetal bovine serum (FBS), penicillin, and streptomycin were obtained from Gibco BRL (Gaithersburg, MD, USA). Mouse recombinant visfatin was obtained from Biovision (Lyon, France). 


\section{Cellular Physiology Cell Physiol Biochem 2019;52:1398-1411 \\ \begin{tabular}{ll|l} 
and Biochemistry & $\begin{array}{l}\text { DOl: 10.33594/000000098 } \\
\text { Published online: 11 May 2019 }\end{array}$ & $\begin{array}{l}\text { O } 2019 \text { The Author(s). Published by } \\
\text { Cell Physiol Biochem Press GmbH\&Co. KG }\end{array}$ \\
\cline { 2 - 3 }
\end{tabular} \\ Lin et al.: Visfatin Promotes Monocyte Adhesion and Its Signaling Pathway}

PD98059, SB203580, LY294002, triciribine (TCN), pyrrolidine dithiocarbamate (PDTC), and Alexa Fluor ${ }^{\circledR}$ 488 goat anti-rabbit IgG were purchased from Enzo Life Sciences, Inc. (Farmingdale, NY, USA). Antibodies of phospho-Akt, p85 subunit of PI3K, Akt, VCAM-1, IKK, I-KB, and histone H2B were purchased from Santa Cruz Biotechnology, Inc. (Santa Cruz, CA, USA). Antibodies of phospho-p85 subunit of PI3K, phospho-p38, p38, ICAM-1, phospho-IKK, phosphо-I-кB, and NF-кB p65 were obtained from Cell Signaling Technology (Danvers, MA, USA). The fluorescent dye 2',7'-bis(2-carboxyethyl)-5(6)-carboxy fluoresceinacetoxymethyl ester (BCECF-AM) was obtained from Molecular Probes (Eugene, OR, USA). Goat serum was purchased from R\&D systems (Minneapolis, MN, USA). Mounting medium was obtained from Vector Labs (Burlingame, CA, USA). NE-PERTM nuclear and cytoplasmic extraction reagent kit was purchased from Thermo Fisher Scientific (Rockford, IL, USA). All other chemicals were from Sigma Chemicals (St. Louis, MO, USA).

\section{Experimental design}

To explore the time-effect of visfatin on the expression of ICAM-1 and VCAM-1, endothelial cells were treated for different times $(0-24 \mathrm{~h})$ with a fixed concentration $(100 \mathrm{ng} / \mathrm{ml})$ of visfatin, and protein levels of ICAM-1 and VCAM-1 were measured. To further explore the dose-effect of visfatin on monocyteendothelial cell adhesion and expression of ICAM-1 and VCAM-1, endothelial cells were treated with different concentrations $(0-100 \mathrm{ng} / \mathrm{ml})$ of visfatin for a fixed time $(24 \mathrm{~h})$. Subsequently, monocyte adhesion and protein levels of ICAM-1 and VCAM-1 were measured. To clarify whether visfatin-induced ICAM-1 and VCAM-1 expression contributes to increased monocyte adhesion, endothelial cells were treated with visfatin in the presence or absence of anti-ICAM-1 or anti-VCAM-1 antibodies. Monocyte adhesion was then measured. Mouse IgG was used in this experiment to serve as the negative control. Furthermore, the effects of visfatin on ROS production, phosphorylation of IKK and I-кB, and nuclear NF-кB expression in endothelial cells were also determined. To gain insight into the signaling pathway involved, endothelial cells were preincubated for $1 \mathrm{~h}$ in the presence or absence of various inhibitors acting on different signaling pathways and then incubated with $100 \mathrm{ng} / \mathrm{ml}$ visfatin in the continued presence or absence of these inhibitors for a further $24 \mathrm{~h}$. Finally, the protein levels of ICAM-1 and VCAM-1 and monocyte adhesion were measured. The inhibitors used were the ERK1/2 inhibitor PD98059 (30 $\mu$ M), PI3K inhibitor LY294002 (30 $\mu \mathrm{M})$, Akt inhibitor TCN $(5 \mu \mathrm{M})$, p38 MAPK inhibitor SB203580 (20 $\mu \mathrm{M})$, NADPH oxidase inhibitor diphenyleneiodonium (DPI; $100 \mathrm{nM}$ ), ROS scavenger N-acetyl-L-cysteine (NAC; $5 \mathrm{mM})$, NF- $\kappa \mathrm{B}$ inhibitor PTDC (10 $\mu \mathrm{M})$, and IKK inhibitor BAY-11-7082 (10 $\mu \mathrm{M})$.

\section{Cell culture}

The human vascular endothelial cell line EA.hy926 (ATCC $₫$ CRL-2922) was used in the whole study. Generally, primary endothelial cells use complex growth media and change phenotype with passage. EA.Hy926 endothelial cells are commonly used stable human cell line, which retain many endothelial cell characteristics (Bouïs et al., 2001).

EA.Hy926 endothelial cells was grown in DMEM containing 10\% FBS, $100 \mu \mathrm{g} / \mathrm{ml}$ streptomycin, and $100 \mathrm{IU} / \mathrm{ml}$ penicillin at $37{ }^{\circ} \mathrm{C}$ in a humidified atmosphere of $95 \%$ air and $5 \% \mathrm{CO}_{2}$. The culture medium was changed twice a week, and the cells were passaged at $80 \%-90 \%$ confluence at a ratio of 1:5. Before each experiment, cells were incubated in serum-free low-glucose DMEM for $4 \mathrm{~h}$.

Primary human umbilical vein endothelial cells (HUVECs) were maintained in medium 200 (Cascade Biologics, Portland, OR, USA) containing $100 \mu \mathrm{g} / \mathrm{ml}$ of streptomycin, $100 \mathrm{IU} / \mathrm{ml}$ of penicillin, $1 \mathrm{X}$ low LSGS, and $10 \%$ fetal bovine serum at $37{ }^{\circ} \mathrm{C}$ in a humidified atmosphere of $95 \%$ air and $5 \% \mathrm{CO}_{2}$. The culture medium was changed twice a week, and the cells were passaged at $80-90 \%$ confluence at a ratio of $1: 3$, and used for experiments at passage 6 to 8. Before each experiment, HUVECs were incubated for $4 \mathrm{~h}$ in medium 200 containing $100 \mu \mathrm{g} / \mathrm{ml}$ of streptomycin, $100 \mathrm{IU} / \mathrm{ml}$ of penicillin, and $0.5 X$ LSGS.

Human monocytic cell line THP-1 was grown in RPMI 1640 medium containing 10\% FBS, $100 \mu \mathrm{g} / \mathrm{ml}$ streptomycin, $100 \mathrm{IU} / \mathrm{ml}$ penicillin, and $5 \times 10^{-5} \mathrm{M}$ 2-mercaptoethanol at $37^{\circ} \mathrm{C}$ in a humidified atmosphere of $95 \%$ air and $5 \% \mathrm{CO}_{2}$.

\section{Monocyte adhesion assay}

THP- 1 cells were labeled for $30 \mathrm{~min}$ at $37^{\circ} \mathrm{C}$ with $10 \mu \mathrm{M}$ BCECF-AM in RPMI 1640 medium and washed by centrifugation. Treated confluent endothelial cells in 24 -well plates were washed three times with culture medium and then incubated with labeled THP- 1 cells $\left(10^{5}\right.$ cells $\left./ 500 \mu \mathrm{l}\right)$ at $37^{\circ} \mathrm{C}$ for $30 \mathrm{~min}$. The non-adherent 


\section{Cellular Physiology Cell Physiol Biochem 2019;52:1398-1411 \\ \begin{tabular}{ll|l} 
and Biochemistry & $\begin{array}{l}\text { DOl: 10.33594/000000098 } \\
\text { Published online: 11 May 2019 }\end{array}$ & $\begin{array}{l}\text { O } 2019 \text { The Author(s). Published by } \\
\text { Cell Physiol Biochem Press GmbH\&Co. KG }\end{array}$ \\
\cline { 2 - 3 }
\end{tabular} \\ Lin et al.: Visfatin Promotes Monocyte Adhesion and Its Signaling Pathway}

THP-1 cells were removed, and the plates were gently washed twice with PBS. The BCECF fluorescence intensity of the adherent cells was measured at excitation/emission wavelengths of 485/535 nm using the Wallac 1420 VICTOR $^{2 \mathrm{TM}}$ fluorometer (Perkin Elmer Inc., Waltham, MA, USA). The images of BCECF-positive cells were observed by fluorescence microscopy (Leica DM 6000 B; Leica Microsystems, Mannheim, BadenWürttemberg, Germany).

\section{Immunoblotting}

Whole cell lysates were made by sonication in lysis buffer (1\% Triton X-100, $50 \mathrm{mM} \mathrm{KCl,} 25 \mathrm{mM}$ Hepes, pH 7.8, $10 \mu \mathrm{g} / \mathrm{ml}$ leupeptin, $20 \mu \mathrm{g} / \mathrm{ml}$ aprotinin, $125 \mu \mathrm{M}$ dithiothreitol, $1 \mathrm{mM}$ phenylmethylsulfonyl fluoride, and $1 \mathrm{mM}$ sodium orthovanadate). Samples (100 $\mathrm{g}$ of total protein) in reducing sample buffer were boiled for $10 \mathrm{~min}$ and resolved on 6\%-10\% SDS-PAGE for $120 \mathrm{~min}$ at $100 \mathrm{~V}$. The contents of the gel were transferred onto a polyvinylidene difluoride membrane at $300 \mathrm{~mA}$ for $120 \mathrm{~min}$. The membrane was pre-blotted in $5 \%$ milk buffer for $60 \mathrm{~min}$ and then immunoblotted with primary antibody for $24 \mathrm{~h}$ followed by secondary antibody for $60 \mathrm{~min}$. Horseradish peroxidase-conjugated secondary antibodies were used in conjunction with chemiluminescence reagent. To detect multiple signals from a single membrane, membranes were treated with a stripping buffer ( $59 \mathrm{mM}$ Tris- $\mathrm{HCl}, 2 \% \mathrm{SDS}$, and $0.75 \% 2$-mercaptoethanol) for $50 \mathrm{~min}$ at $50{ }^{\circ} \mathrm{C}$ prior to re-blotting with a different antibody.

\section{ROS production and NADPH oxidase activity}

Treated cells were incubated with $10 \mu \mathrm{M}$ dihydroethidium for $30 \mathrm{~min}$ at $37{ }^{\circ} \mathrm{C}$ and washed once with PBS. The fluorescence intensity of the cells was measured at excitation/emission wavelengths of 535/610 nm using the Wallac 1420 VICTOR $^{2 \mathrm{TM}}$ fluorometer (Perkin Elmer Inc., Waltham, MA, USA). The images of ethidium-positive cells were observed by fluorescence microscopy (Leica DM 6000 B; Leica Microsystems, Mannheim, Baden-Württemberg, Germany). NADPH oxidase activity was measured with an NADP/NADPH quantification colorimetric kit (BioVision, California, USA).

\section{Lentiviral infection}

Lentiviral vectors containing NOX4 shRNA were obtained from the National RNAi Core Facility (Academia Sinica, Taipei, Taiwan). The endothelial cells were infected with lentivirus in the presence of polybrene $(8 \mathrm{mg} / \mathrm{ml})$. Twenty-four hours post-infection, cells were treated with or without visfatin for further $24 \mathrm{~h}$. Expression of NOX4 and ICAM-1 was measured.

\section{Immunocytochemistry}

Treated cells were fixed with 4\% paraformaldehyde for $20 \mathrm{~min}$ in room temperature and washed three times with PBS. The cells were permeabilized with $0.5 \%$ Triton X-100 for $15 \mathrm{~min}$ and washed three times with PBS. Subsequently, 5\% goat serum was used to pre-block for $30 \mathrm{~min}$, and the cells were immediately incubated with rabbit polyclonal anti-NF- $\kappa B$ p65 primary antibody (dissolve in goat serum, $1: 100$ ) at $4{ }^{\circ} \mathrm{C}$ overnight. After washing, the cells were incubated with Alexa Fluor ${ }^{8} 488$ goat anti-rabbit IgG (dissolve in goat serum, 1:200) for $1 \mathrm{~h}$ in room temperature. The cells with mounting medium containing 4',6-diamidino2-phenylindole (DAPI) were detected by fluorescence microscopy (Leica DM 6000 B; Leica Microsystems, Mannheim, Baden-Württemberg, Germany).

\section{Preparation of nuclear extracts}

Nuclear protein was isolated following the manufacturing instructions of NE-PERTM nuclear and cytoplasmic extraction reagent kit (Rockford, IL, USA). Histone H2B served as the loading control for nuclear protein.

\section{Statistical analysis}

Experiments were repeated at least three times. The results were expressed as the mean \pm SEM. Statistical significance was assessed by one-way ANOVA or Student's $t$-test, with a value of $P<0.05$ being statistically significant. 


\section{Results}

Adhesion of monocytes to visfatin-treated endothelial cells

Endothelial cells were incubated for $24 \mathrm{~h}$ with various concentrations of visfatin $(0$ $100 \mathrm{ng} / \mathrm{ml}$ ). Fig. $1 \mathrm{~A}$ and $1 \mathrm{~B}$ show that incubation with $25 \mathrm{ng} / \mathrm{ml}$ visfatin caused a significant increase in monocyte adhesion. This response was dose-dependent, with an ED50 (halfmaximal effective dose) of $33.7 \mathrm{ng} / \mathrm{ml}$. The maximal adhesion of monocytes in the presence of $100 \mathrm{ng} / \mathrm{ml}$ visfatin was almost twofold higher than that in the control $(P<0.05)$ (Fig. 1B).

Effects of ERK1/2, p38 MAPK, PI3K, and Akt inhibitors on visfatin-induced monocyteendothelial cell adhesion

As shown in Fig. 1C and 1D, pretreatment of endothelial cells with the ERK1/2 inhibitor PD98059 (PD, $30 \mu \mathrm{M}$ ) had no effect on visfatin-induced monocyte-endothelial cell adhesion. However, pretreatment of endothelial cells with the PI3K inhibitor LY294002 (LY, $30 \mu \mathrm{M})$, Akt inhibitor triciribine (TCN, $5 \mu \mathrm{M}$ ), or p38 MAPK inhibitor SB203580 (SB, $20 \mu \mathrm{M})$ significantly prevented visfatin-induced monocyte-endothelial cell adhesion (Fig. 1D, $P<0.05$ ), showing that both PI3K/Akt and p38 MAPK activation was necessary for visfatin-stimulated monocyte adhesion to endothelial cells.

Effects of visfatin on ICAM-1 and VCAM-1 protein expression in endothelial cells

Endothelial cells were treated for different times (0-24 h) with a fixed concentration $(100 \mathrm{ng} / \mathrm{ml})$ of visfatin, and protein levels of ICAM-1 and VCAM- 1 were measured. As shown in Supplementary Fig. S1A and S1B, a significant increase in ICAM-1 and VCAM-1 expression was observed after 8 and $12 \mathrm{~h}$ of visfatin incubation, respectively (for all supplemental material see www.cellphysiolbiochem.com). Endothelial cells were then incubated for $24 \mathrm{~h}$ with various concentrations of visfatin $(0-100 \mathrm{ng} / \mathrm{ml})$. Supplementary Fig. S1C and S1D show that incubation with $50 \mathrm{ng} / \mathrm{ml}$ visfatin caused a significant increase in ICAM-1 and VCAM-1 expression compared with the vehicle control. This response was dose-dependent, with an ED50 of $60.2 \mathrm{ng} / \mathrm{ml}$ for ICAM-1 and $35.9 \mathrm{ng} / \mathrm{ml}$ for VCAM-1. The maximal ICAM-1 and VCAM1 expression in the presence of $100 \mathrm{ng} / \mathrm{ml}$ visfatin was almost 2.2-fold higher than that in the control $(P<0.05)$ (Supplementary Fig. S1C and S1D). Pretreatment of endothelial cells with the ERK1/2 inhibitor PD98059 had no effect on visfatin-induced ICAM-1 and VCAM1 expression (Fig. 2A and 2B). However, pretreatment of endothelial cells with the PI3K inhibitor LY294002 or the p38 MAPK inhibitor SB203580 significantly prevented visfatininduced ICAM-1 and VCAM-1 expression (Fig. 2A and 2B). These observations suggested that visfatin upregulated ICAM-1 and VCAM-1 protein expression via both the PI3K- and P38 MAPK-dependent pathways, not the ERK1/2-dependent pathway.

Furthermore, simultaneous treatment of endothelial cells with visfatin and $10 \mu \mathrm{g} / \mathrm{ml}$ anti-ICAM-1 or anti-VCAM-1 antibodies resulted in a significant suppression in the visfatininduced adhesion of fluorescence-labeled monocytes to endothelial cells (Fig. 2C and 2D). Treatment with mouse IgG isotype controls was used to serve as a negative control to deduct non-specific effect of IgG on monocytes adhesion to endothelial cells. Results showed that mouse IgG isotype controls did not affect visfatin-induced adhesion of monocytes to endothelial cells (Fig. 2C and 2D). This result demonstrated that visfatin upregulated ICAM-1 and VCAM-1 expression and subsequently caused increased monocyte adhesion to endothelial cells.

Involvement of ROS production in visfatin-induced monocyte-endothelial cell adhesion

As shown in Fig. 3A, visfatin treatment caused a significant increase in ROS production in endothelial cells. Visfatin-promoted monocyte adhesion was significantly prevented by pretreatment with ROS scavenger NAC (5 mM; Fig. 3B). Similarly, visfatin-stimulated ICAM-1 and VCAM-1 protein expression was also suppressed by pretreatment with NAC (Fig. 3C and 3D), showing that ROS played a mechanical role in visfatin-induced monocyte-endothelial cell adhesion. 
Fig. 1. Visfatin stimulates monocyte adhesion to endothelial cells through the PI3K/Akt- and p38-dependent pathways. (A and B) Cells were incubated with various concentrations of visfatin $(0-100 \mathrm{ng} / \mathrm{ml})$ for $24 \mathrm{~h}$, then the adhesion of THP-1 monocytes was measured. (C and D) Cells were pre-incubated for $1 \mathrm{~h}$ in the presence of the ERK1/2 inhibitor PD98059 (PD, $30 \mu \mathrm{M})$, PI3K inhibitor LY294002 (LY, $30 \mu \mathrm{M})$, Akt inhibitor triciribine (TCN, $5 \mu \mathrm{M}$ ), or p38 MAPK inhibitor SB203580 (SB, $20 \mu \mathrm{M}$ ), followed by incubation in the absence or presence of visfatin (100 ng/ $\mathrm{ml}$ ) in the continued absence or presence of the inhibitor for a further $24 \mathrm{~h}$. Subsequently, the adhesion of THP-1 monocytes was measured. The results are the mean \pm SEM for three separate experiments, each in triplicate. ${ }^{*} \mathrm{P}<0.05$ compared with the zero control (B) or the untreated control (D); ${ }^{\#} \mathrm{P}<0.05$ compared with the visfatin alone group; ${ }^{\$} \mathrm{P}<0.05$ compared with the $50 \mathrm{ng} / \mathrm{ml}$ visfatin-treated group.

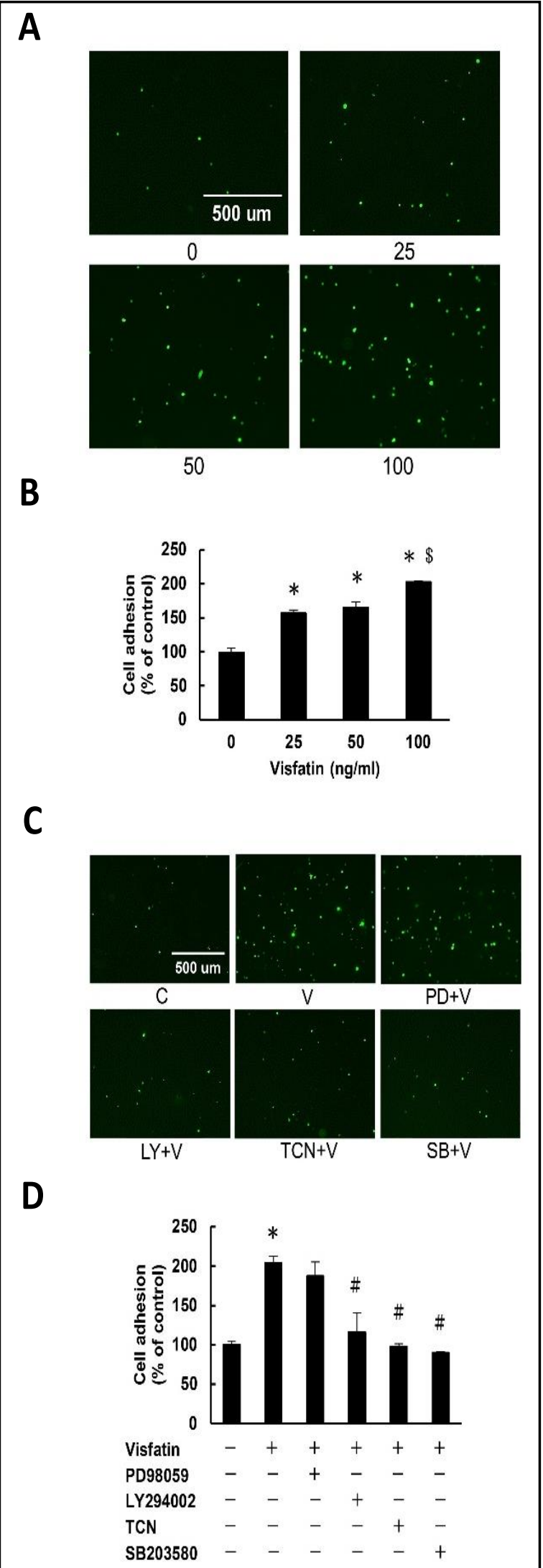


Fig. 2. Visfatin upregulates ICAM-1 and VCAM-1 expression in endothelial cells through the PI3K/ Akt- and p38-dependent pathways. (A and B) Cells were pre-incubated for $1 \mathrm{~h}$ in the absence or presence of the ERK1/2 inhibitor PD98059 (PD, $30 \mu \mathrm{M})$, PI3K inhibitor LY294002 (LY, $30 \mu \mathrm{M}$ ), or p38 MAPK inhibitor SB203580 (SB, 20 $\mu \mathrm{M}$ ), followed by incubation in the absence or presence of visfatin $(100 \mathrm{ng} / \mathrm{ml})$ in the continued absence or presence of the inhibitor for a further $24 \mathrm{~h}$. The expression of ICAM-1 and VCAM-1 were measured. (C and D) Endothelial cells were left untreated or were incubated with $100 \mathrm{ng} / \mathrm{ml}$ visfatin alone or together with $10 \mu \mathrm{g} / \mathrm{ml}$ anti-ICAM-1, anti-VCAM-1 monoclonal antibodies, or $10 \mu \mathrm{g} / \mathrm{ml}$ mouse IgG for $24 \mathrm{~h}$. The adhesion of THP-1 monocytes was measured. The results are the mean \pm SEM for three separate experiments, each in triplicate. ${ }^{*} \mathrm{P}<0.05$ compared with the untreated control; $\quad$ P $<0.05$ compared with the visfatin alone group.

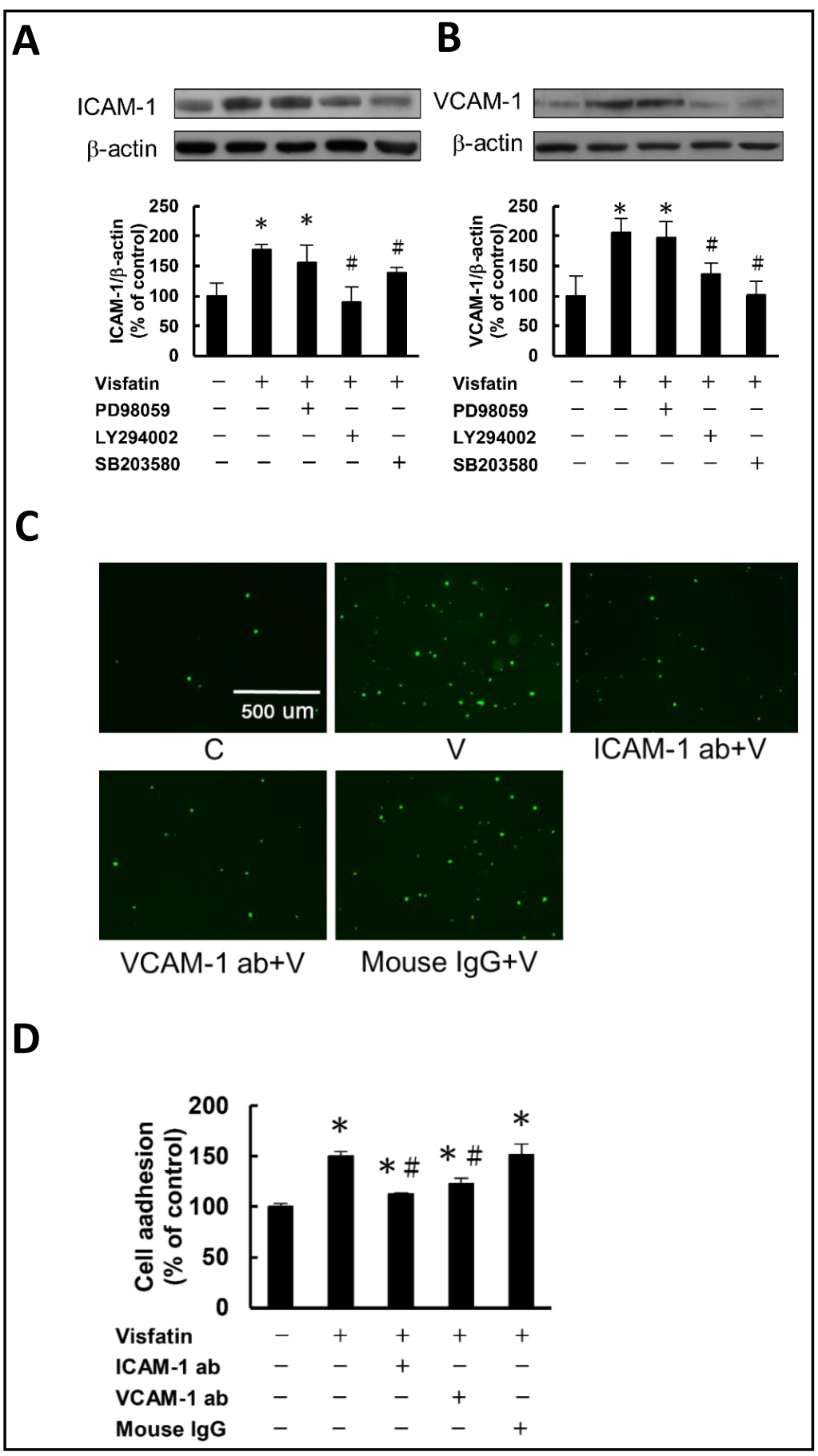

Involvement of PI3K- and p38 MAPK-dependent pathways in visfatin-stimulated ROS production in endothelial cells

As shown in Fig. 4A, 4B and Supplementary Fig. 2, visfatin significantly stimulated phosphorylation of p85 subunit of PI3K, Akt and p38 in endothelial cells. Pretreatment with PI3K inhibitor LY294002 or p38 MAPK inhibitor SB203580, but not ROS scavenger NAC, significantly inhibited visfatin-induced p85 subunit of PI3K and Akt phosphorylation; pretreatment with p38 MAPK inhibitor SB203580, but not PI3K inhibitor LY294002 or ROS scavenger NAC, significantly inhibited visfatin-induced p38 phosphorylation. In addition, visfatin-induced ROS production was significantly blocked by pretreatment with PI3K 


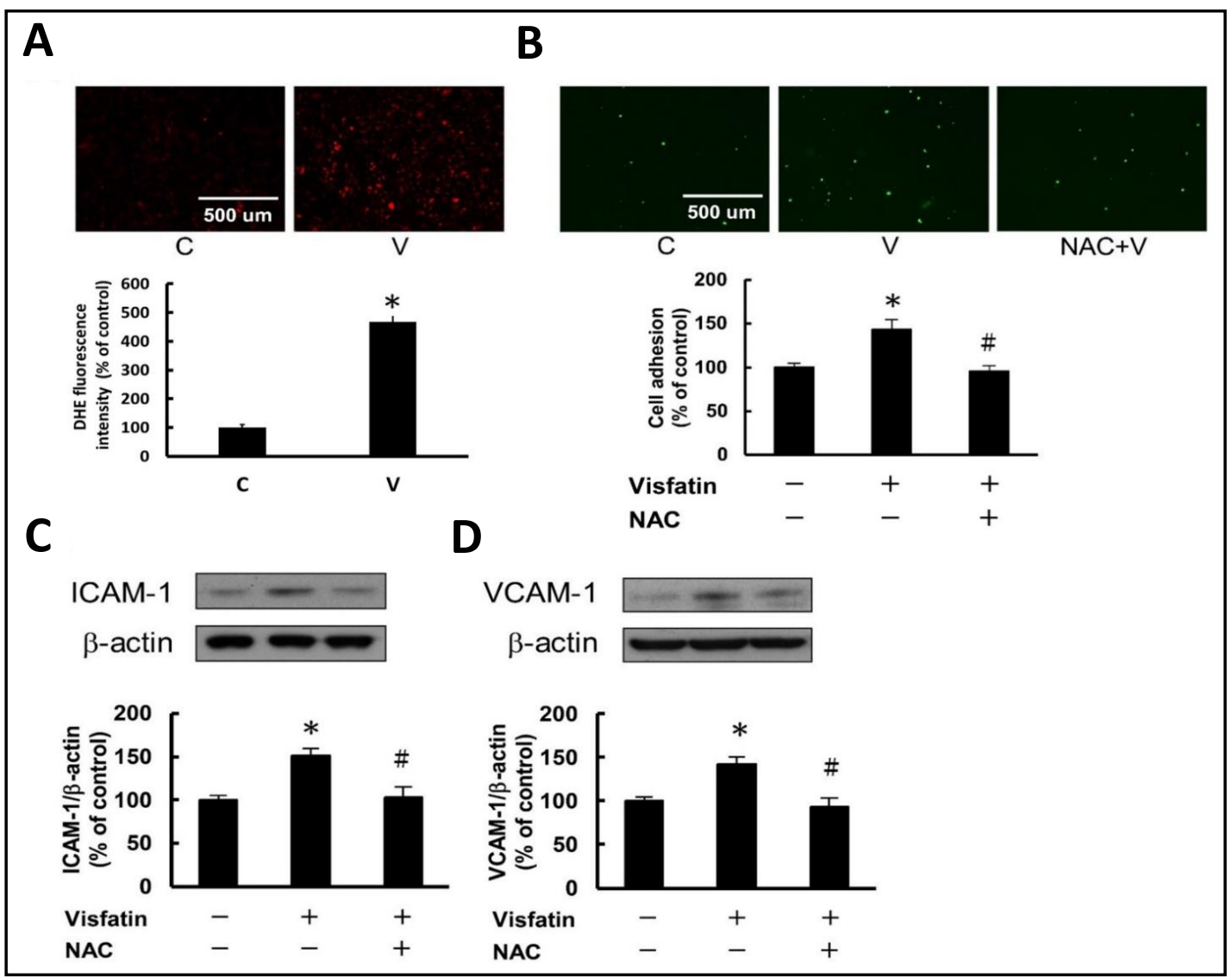

Fig. 3. Involvement of ROS in visfatin-stimulated ICAM-1 and VCAM-1 expression and monocyte adhesion in endothelial cells. (A) Cells were incubated in the absence or presence of $100 \mathrm{ng} / \mathrm{ml}$ visfatin for $24 \mathrm{~h}$. (B-D) Cells were pre-incubated for $1 \mathrm{~h}$ in the absence or presence of the ROS scavenger N-acetyl-L-cysteine (NAC, $5 \mathrm{mM}$ ), followed by incubation in the absence or presence of visfatin $(100 \mathrm{ng} / \mathrm{ml})$ in the continued absence or presence of the inhibitor for a further $24 \mathrm{~h}$. (A) The production of ROS, (B) adhesion of THP-1 monocytes, and the protein expression of (C) ICAM-1 and (D) VCAM-1 were measured. The results are the mean \pm SEM for three separate experiments, each in triplicate. ${ }^{*} \mathrm{P}<0.05$ compared with the untreated control; ${ }^{*} \mathrm{P}<0.05$ compared with the visfatin alone group.

inhibitor LY294002 (LY), p38 MAPK inhibitor SB203580 (SB), ROS scavenger NAC, but not ERK1/2 inhibitor PD98059 (PD) (Fig. 4C). Taken together, these results suggested that visfatin-activated p38MAPK caused PI3K/Akt phosphorylation and activation and finally resulted in ROS production in endothelial cells.

Since NADPH oxidase (NOX) is a major source of ROS generation in vascular endothelial cells [16], we performed further experiments to investigate the effect of visfatin on NOX activity. Our results showed that visfatin increased NOX activity (Fig. 5A). Pretreatment with PI3K inhibitor LY294002, Akt inhibitor TCN, p38 MAPK inhibitor SB203580, NOX inhibitor DPI significantly inhibited visfatin-increased NOX activity (Fig. 5A). Furthermore, pretreatment with NOX inhibitor DPI also significantly inhibited visfatin-increased ROS production (Supplementary Fig. S3A), ICAM-1 and VCAM-1 expressions (Fig. 5B) and monocyte adhesion to endothelial cells (Supplementary Fig. S3B). Then we clarify the NOX isoform involved within the visfatin-stimulated monocyte adhesion on endothelial cells. Our data showed that treatment of visfatin increased NOX4 expression in endothelial cells (Fig. 5C). Knockdown with NOX4 shRNA via lentiviral infection successfully inhibited visfatinstimulated NOX4 and ICAM-1 expression (Fig. 5D). These findings indicated that NOX4 activation was involved within the processes of visfatin-induced ROS production, ICAM-1 and VCAM-1 expression and monocyte adhesion to endothelial cells. 
Fig. 4. Involvement of p38/ PI3K/Akt signaling cascade in visfatin-stimulated ROS production in endothelial cells. Cells were preincubated for $1 \mathrm{~h}$ in the absence or presence of the ERK1/2 inhibitor PD98059 (PD, $30 \mu \mathrm{M}$ ), PI3K inhibitor LY294002 (LY, $30 \mu \mathrm{M}$ ), p38 MAPK inhibitor SB203580 (SB, $20 \mu \mathrm{M}$ ), or ROS scavenger NAC ( $5 \mathrm{mM}$ ). Cells were then incubated in the absence or presence of visfatin (100 ng/ $\mathrm{ml}$ ) in the continued absence or presence of the inhibitor for a further (A and B) 30 min or (C) $24 \mathrm{~h}$. The phosphorylation of p85 subunit of PI3K and Akt was analyzed by western blot with antibodies against phosphorylated human p85 subunit of PI3K and Akt or total human p85 subunit of PI3K and Akt (A and B) and the production of ROS were detected by fluorescence intensity (C). The results are the mean \pm SEM for three separate experiments, each in triplicate. ${ }^{*} \mathrm{P}<0.05$ compared with the untreated control; ${ }^{\#} \mathrm{P}<0.05$ compared with the visfatin alone group.

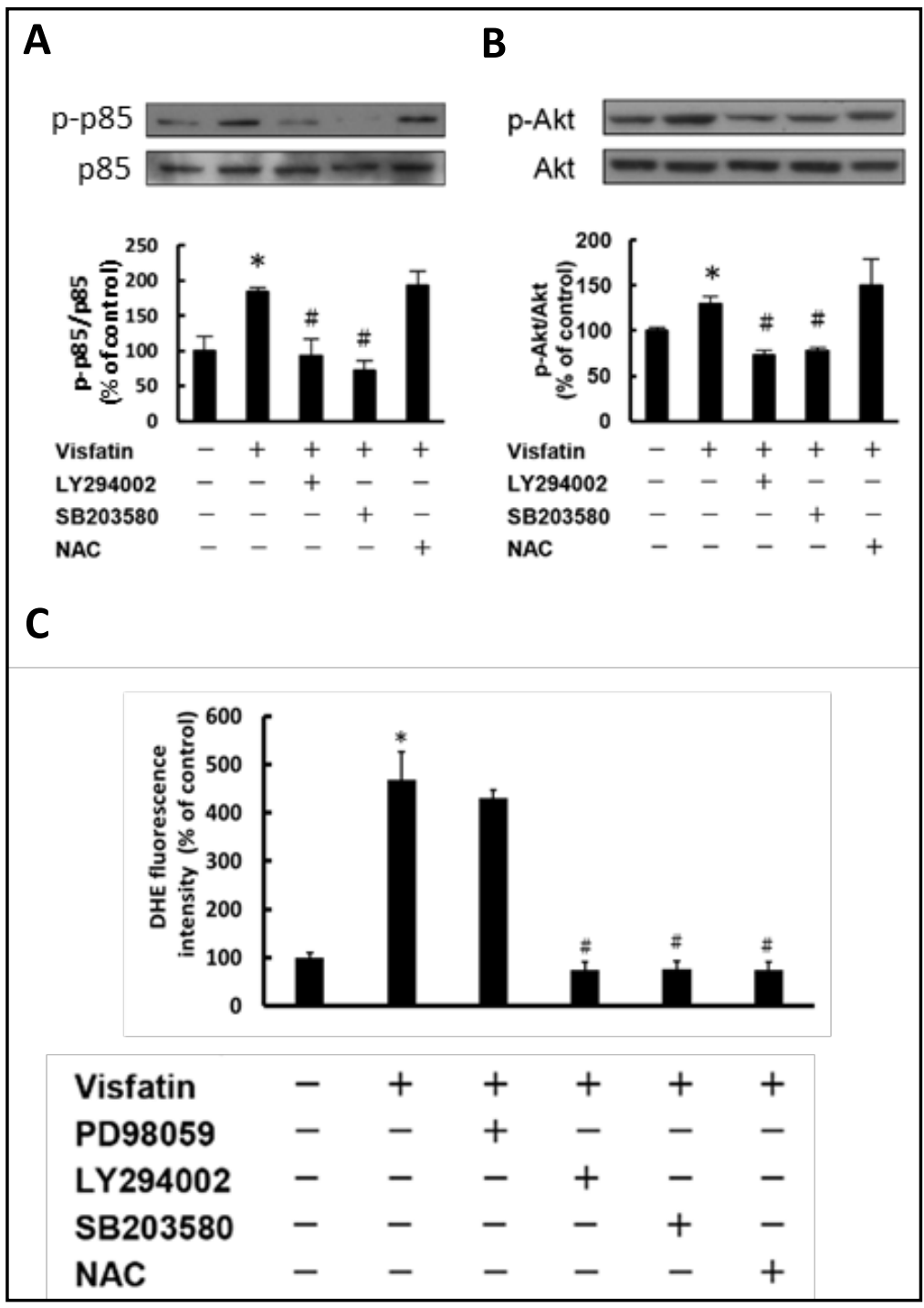

Involvement of IKK and I- $\kappa B$ phosphorylation and nuclear NF- $\kappa B$ expression in visfatininduced monocyte-endothelial cell adhesion

As shown in Fig. 6A and 6B, treatment with visfatin caused a significant increase in phosphorylation of IKK and I-KB in the endothelial cells. These effects were prevented by pretreatment with PI3K inhibitor LY294002, p38 MAPK inhibitor SB203580, and ROS scavenger NAC. Visfatin induced a significant increase in nuclear NF-кB expression, and this effect was also blocked by pretreatment with PI3K inhibitor LY294002, p38 MAPK inhibitor SB203580, ROS scavenger NAC, and IKK inhibitor BAY-11-7082 (Fig. 6C and Supplementary Fig. S4).

Furthermore, visfatin-stimulated ICAM-1 and VCAM-1 protein expression was significantly blocked by pretreatment with NF- $\kappa B$ inhibitor PDTC $(10 \mu \mathrm{M})$, IKK inhibitor BAY-11-7082 (10 $\mu \mathrm{M})$, and Akt inhibitor TCN (Supplementary Fig. S5A and S5B). Visfatinstimulated monocyte adhesion was suppressed by pretreatment with PDTC and BAY-117082 (Supplementary Fig. S5C and S5D), showing that IKK/NF- $\kappa B$ activation was involved within visfatin-induced monocyte-endothelial cell adhesion. Taken together, these results suggested that visfatin-induced activation of p38/PI3K/Akt signaling and subsequently stimulated ROS production and IKK/NF-кB activation led to the upregulation of adhesion molecule expression and enhancement of monocyte-endothelial cell adhesion. 
Fig. 5. Involvement of p38/PI3K/Akt signaling cascade in visfatin-stimulated NOX activity and involvement of NOX in visfatinstimulated ROS production, ICAM1 and VCAM-1 expression, and monocyte adhesion in endothelial cells. (A) Cells were preincubated for $1 \mathrm{~h}$ in the absence or presence of the PI3K inhibitor LY294002 (LY, $30 \mu \mathrm{M}$ ), Akt inhibitor TCN (5 $\mu \mathrm{M})$, p38 MAPK inhibitor SB203580 (SB, $20 \mu \mathrm{M}$ ), or NADPH oxidase inhibitor DPI (100 $n M)$. Cells were then incubated in the absence or presence of visfatin (100 ng/ $\mathrm{ml}$ ) in the continued absence or presence of the inhibitor for a further $24 \mathrm{~h}$. (A) The NADPH oxidase activity, (B) the protein expression of ICAM-1 and VCAM-1, and (C) the protein expression of NOX4
C
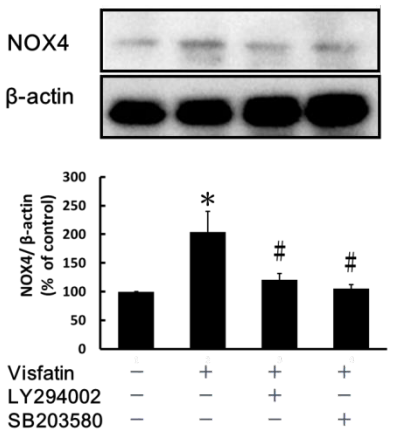

B

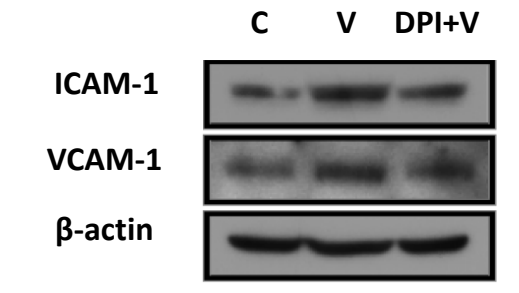

D

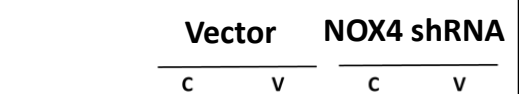

ICAM-1

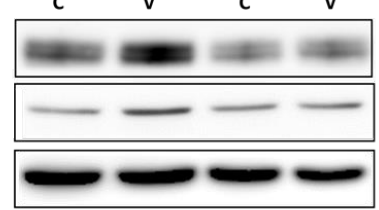

$\beta$-actin
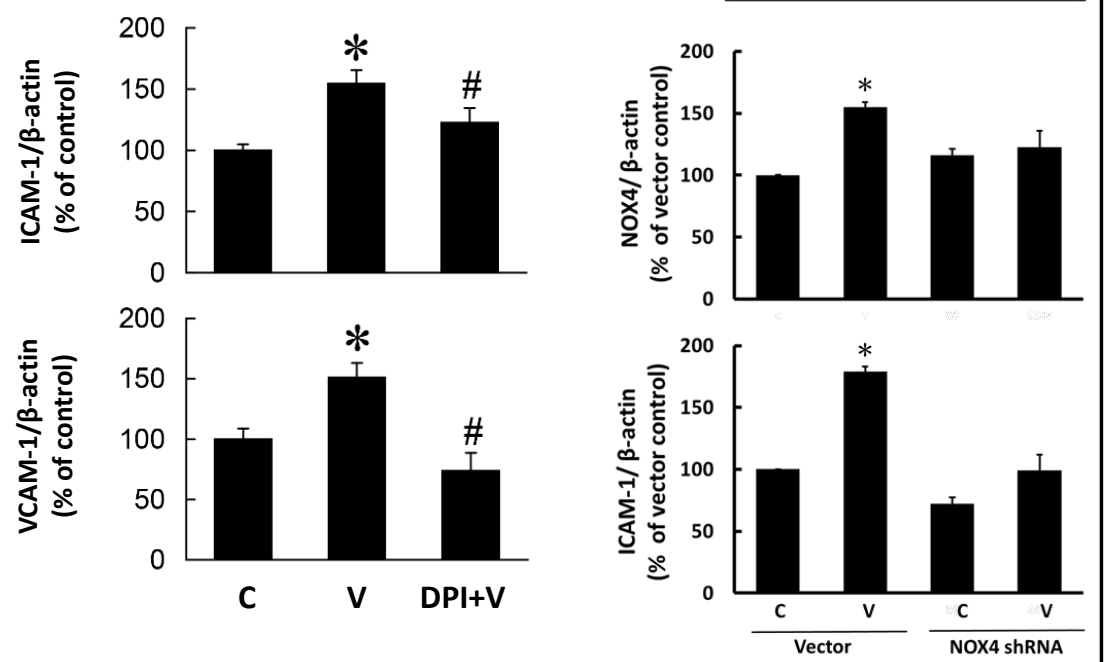

were measured. (D) Cells were transfected with iNOS shRNA or empty vector via lentiviral infection for 24 $\mathrm{h}$, and incubated for a further $24 \mathrm{~h}$ in the absence or presence of visfatin $(100 \mathrm{ng} / \mathrm{ml})$. The expression of NOX4 and ICAM-1 was measured. The results are the mean \pm SEM for three separate experiments, each in triplicate. ${ }^{*} \mathrm{P}<0.05$ compared with the untreated control; ${ }^{*} \mathrm{P}<0.05$ compared with the visfatin alone group.

Furthermore, we performed experiments to test visfatin effect on ICAM-1 and VCAM-1 expressions and monocyte adhesion and the underlying signaling mechanisms in primary HUVECs. Results showed that incubation with visfatin $(100 \mathrm{ng} / \mathrm{ml})$ for $24 \mathrm{~h}$ caused a significant increase on expression of ICAM-1 and VCAM-1, and monocyte adhesion to HUVECs (Supplementary Fig. S6). Pretreatment of HUVECs with PI3K inhibitor LY294002, Akt inhibitor TCN, p38 MAPK inhibitor SB203580, NADPH oxidase inhibitor DPI, ROS scavenger NAC, NF- $\mathrm{KB}$ inhibitor PTDC, and IKK inhibitor BAY-11-7082 significantly inhibited visfatin-increased ICAM-1 and VCAM-1 expression and monocyte adhesion to HUVECs (Supplementary Fig. S6). 
Fig. 6. Visfatin promotes NF$\kappa \mathrm{B}$ activation via the $\mathrm{p} 38 /$ PI3K/Akt/ROS signaling cascade. Endothelial cells were pre-incubated for $1 \mathrm{~h}$ in the absence or presence of PI3K inhibitor LY294002 (LY, $30 \mu \mathrm{M})$, p38 MAPK inhibitor SB203580 (SB, $20 \mu \mathrm{M})$, ROS scavenger NAC (5 mM), or IKK inhibitor BAY-11-7082 (BAY, $10 \mu \mathrm{M}$ ). Cells were then incubated in the absence or presence of visfatin (100 ng/ $\mathrm{ml}$ ) in the continued absence or presence of the inhibitor for a further (A and B) $30 \mathrm{~min}$ or (C) $24 \mathrm{~h}$. Subsequently, the phosphorylation of (A) IKK, (B) $I-\kappa B$, and (C) the nuclear protein expression of NF$\kappa B$ p65 were measured. The results are the mean \pm SEM for three separate experiments, each in triplicate. ${ }^{*} \mathrm{P}<0.05$ compared with the untreated control; $\quad \# \mathrm{P}<0.05$ compared with the visfatin alone group.

\section{A}
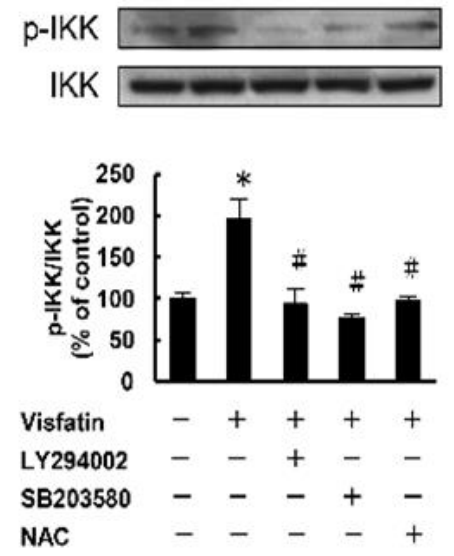

B

\section{$\mathrm{p}-\mathrm{I \kappa} \mathrm{B}$ \\ IKB}
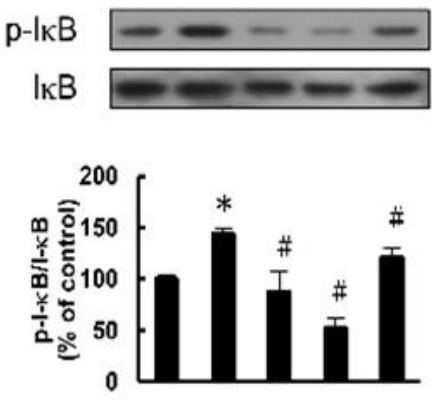

Visfatin -++++

LY294002 - - + - -

SB203580 - --+-

NAC

$-\quad-\quad+$
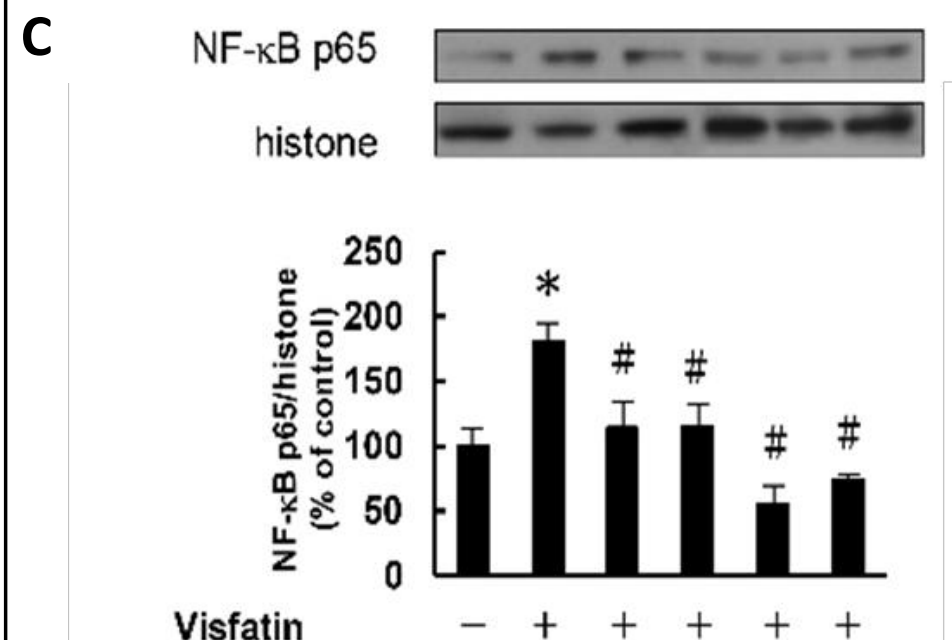

$\begin{array}{lllllll}\text { Visfatin } & - & + & + & + & + & + \\ \text { LY294002 } & - & - & + & - & - & - \\ \text { SB203580 } & - & - & - & + & - & - \\ \text { NAC } & - & - & - & - & + & - \\ \text { BAY-11-7082 } & - & - & - & - & - & +\end{array}$

\section{Discussion}

The major findings of the present study were that visfatin stimulated endothelial ICAM-1 and VCAM-1 expression and subsequently increased monocyte adhesion to endothelial cells through activation of p38/PI3K/Akt signaling, ROS production, and IKK/NF- $\mathrm{BB}$ activation. Both Kim's and Lee's studies demonstrated that visfatin increases ICAM-1 and VCAM-1 expression and monocyte adhesion in different types of endothelial cells [13-14]. Part of our findings was compatible with their findings. However, the causal effect between increased ICAM-1 and VCAM-1 expression and increased monocyte adhesion to endothelial cells was not proved in both Kim's and Lee's studies [13-14]. In our study, neutralization of ICAM1 and VCAM-1 with specific antibodies significantly blocked visfatin-induced monocyte adhesion to endothelial cells (Fig. 2C and 2D). We provided direct evidence demonstrating that visfatin stimulated ICAM-1 and VCAM-1 expression and subsequently caused enhanced monocyte adhesion to endothelial cells. 
Several signaling mechanisms mediating visfatin actions have been proposed. For example, treatment with visfatin could induce activations of p38 MAPK, PI3K, and ERK1/2 pathways [12-15]. Our data demonstrated that visfatin increased ICAM-1 and VCAM-1 expression and subsequently enhanced monocyte adhesion through the PI3K/Akt- and p38 MAPK-dependent pathways, but not the ERK 1/2-dependent pathway (Fig. 1, 2, and Supplementary Fig. S1). In the present study, we demonstrated that treatment with visfatin significantly induced ROS production in endothelial cells. This finding was compatible with Kim's findings [13]. However, the visfatin dose used in Kim's study was relatively high $(500 \mathrm{ng} / \mathrm{ml})$. The circulating levels of visfatin vary from about $16 \mathrm{ng} / \mathrm{ml}$ in healthy humans to about $32 \mathrm{ng} / \mathrm{ml}$ in type 2 diabetic patients $[4,6]$. The dosage of visfatin used in Kim's study was higher than circulating levels of visfatin [13]. Compared with the high dose of visfatin in Kim's study, the visfatin dose used in the present study fell within the pathophysiological range [13]. Besides, both Kim's and Lee's studies only suggested the association between NF-кB activation and visfatin-increased monocyte adhesion to endothelial cells [13-14]. In our study, we further demonstrated that inhibition of IKK and NF- $\kappa \mathrm{B}$ activities prevented visfatin-stimulated ICAM-1 and VCAM-1 expression and visfatin-induced monocyteendothelial cell adhesion (Supplementary Fig. S5). Furthermore, we clarified the visfatinevoked downstream signal, which was early compared with NF-кB activation. We also demonstrated that visfatin activated the p38/PI3K/Akt pathway to increase NADPH oxidase activity and ROS production, subsequently phosphorylated IKK and I-кB, increased nuclear NF-кB expression, and finally increased ICAM-1 and VCAM-1 expression and monocyte adhesion in endothelial cells (Fig. 4-6 and Supplementary Fig. S2-S5).

\section{Conclusion}

In conclusion, the present study demonstrated that visfatin stimulated monocyte adhesion to vascular endothelial cells, and this phenomenon resulted from the upregulation of ICAM-1 and VCAM-1 via activating p38/PI3K/Akt signaling and subsequently causing ROS production and IKK/NF-кB activation (Fig. 7). Our findings also proved that visfatin played a pivotal role in monocyte-endothelial cell adhesion, which is an early step in the development of endothelial dysfunction and atherosclerosis. In combination with our recent findings that visfatin promotes foam cell formation by dysregulating CD36, scavenger receptor A, and ATP-

Fig. 7. Working model of visfatin-induced monocyte adhesion.Visfatin stimulates p38 phosphorylation to further activate the PI3K/ Akt signaling, NADPH oxidase activity and ROS generation. Increase of IKK phosphorylation by ROS further phosphorylates $I \kappa B$ to cause NF- $\kappa$ B translocation into the nucleus, leading to the transcription of ICAM-1 and VCAM-1 and resulting in monocyte adhesion.

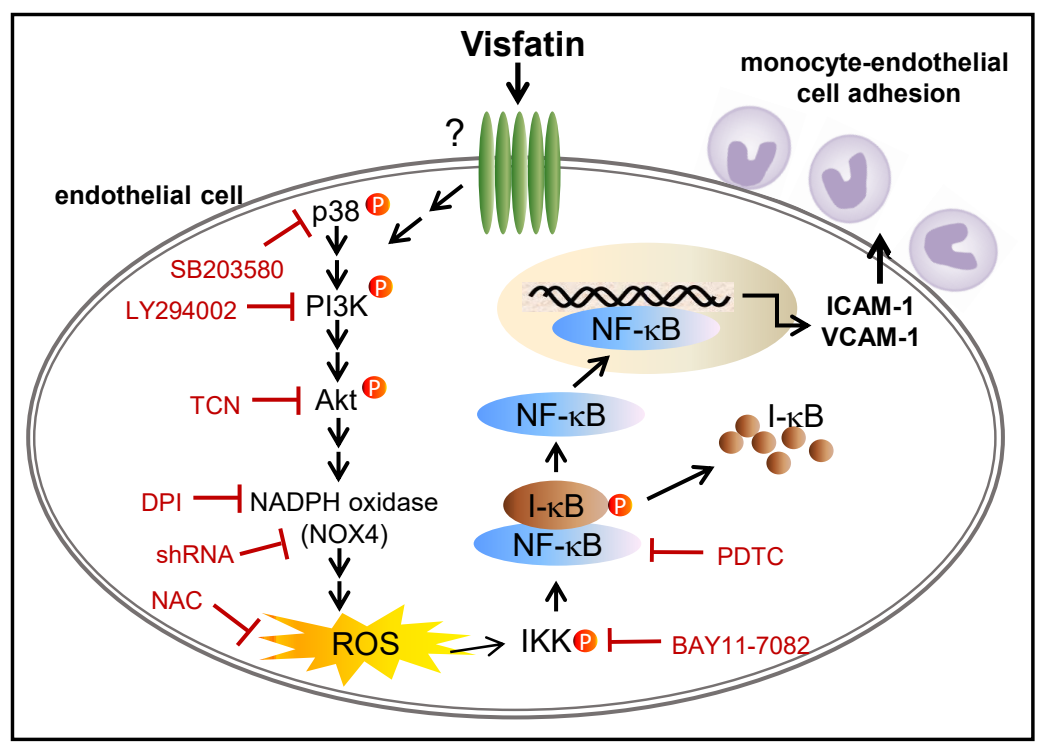




\section{Cellular Physiology Cell Physiol Biochem 2019;52:1398-1411 \\ \begin{tabular}{ll|l} 
and Biochemistry & $\begin{array}{l}\text { DOl: 10.33594/000000098 } \\
\text { Published online: 11 May 2019 }\end{array}$ & $\begin{array}{l}\text { O } 2019 \text { The Author(s). Published by } \\
\text { Cell Physiol Biochem Press GmbH\&Co. KG }\end{array}$ \\
\cline { 2 - 3 } &
\end{tabular} \\ Lin et al.: Visfatin Promotes Monocyte Adhesion and Its Signaling Pathway}

binding cassette transporters A1 and G1 [17], the abnormal secretion of obesity-associated adipokines, such as visfatin, may serve as one of the possible mechanisms mediating obesityassociated cardiovascular diseases, such as atherosclerosis.

\section{Acknowledgements}

This study was supported by research grants from the Yen Tjing Ling Medical Foundation (CI-100-3) and the Ministry of Science and Technology (MOST 107-3011-B-010-001; 1-32), and "Development and Construction Plan" of the School of Medicine, National YangMing University (No. 107F-M01), Taipei, Taiwan. We thank the National RNAi Core Facility, Academia Sinica for providing lentiviral shRNAs.

\section{Disclosure Statement}

The authors declare that no conflicts of interest exist.

\section{References}

- 1 Stephens JM, Vidal-Puig AJ: An update on visfatin/pre-B cell colony-enhancing factor, an ubiquitously expressed, illusive cytokine that is regulated in obesity. Curr Opin Lipidol 2006;17:128-131.

- 2 Fukuhara A, Matsuda M, Nishizawa M, Segawa K, Tanaka M, Kishimoto K, Matsuki Y, Murakami M, Ichisaka T, Murakami H, Watanabe E, Takagi T, Akiyoshi M, Ohtsubo T, Kihara S, Yamashita S, Makishima M, Funahashi T, Yamanaka S, Hiramatsu R, et al.: Visfatin: a protein secreted by visceral fat that mimics the effects of insulin. Science 2005;307:426-430.

- 3 Luk T, Malam Z, Marshall JC: Pre-B cell colony-enhancing factor (PBEF)/visfatin: a novel mediator of innate immunity. J Leukoc Biol 2008;83.804-816.

4 Berndt J, Klöting N, Kralisch S, Kovacs P, Fasshauer M, Schön MR, Stumvoll M, Blüher M: Plasma visfatin concentrations and fat depot-specific mRNA expression in humans. Diabetes 2005;54:2911-2916.

- 5 Bełtowski J: Apelin and visfatin: unique "beneficial” adipokines upregulated in obesity? Med Sci Monit 2006;12:RA112-RA119.

6 Chen MP, Chung FM, Chang DM, Tsai JC, Huang HF, Shin SJ, Lee YJ: Elevated plasma level of visfatin/ pre-B cell colony-enhancing factor in patients with type 2 diabetes mellitus. J Clin Endocrinol Metab 2006;91:295-299.

- 7 Matsuzawa Y: The metabolic syndrome and adipocytokines. FEBS Lett 2006;580:2917-2921.

- 8 Kang YS, Song HK, Lee MH, Ko GJ, Han JY, Han SY, Han KH, Kim HK, Cha DR: Visfatin is upregulated in type-2 diabetic rats and targets renal cells. Kidney Int 2010;78:170-181.

- 9 Samal B, Sun Y, Stearns G, Xie C, Suggs S, McNiece I: Cloning and characterization of the cDNA encoding a novel human pre-B-cell colony-enhancing factor. Mol Cell Biol 1994;14:1431-1437.

- 10 McGlothlin JR, Gao L, Lavoie T, Simon BA, Easley RB, Ma SF, Rumala BB, Garcia JG, Ye SQ: Molecular cloning and characterization of canine pre-B-cell colony-enhancing factor. Biochem Genet 2005;43:127-141.

- 11 Catalán V, Gómez-Ambrosi J, Rodríguez A, Ramírez B, Silva C, Rotellar F, Cienfuegos JA, Salvador J, Frühbeck G: Association of increased visfatin/PBEF/NAMPT circulating concentrations and gene expression levels in peripheral blood cells with lipid metabolism and fatty liver in human morbid obesity. Nutr Metab Cardiovasc Dis 2011;21:245-253.

- 12 Moschen AR, Kaser A, Enrich B, Mosheimer B, Theurl M, Niederegger H, Tilg H: Visfatin, an adipocytokine with proinflammatory and immunomodulating properties. J Immunol 2007;178:1748-1758.

13 Kim SR, Bae YH, Bae SK, Choi KS, Yoon KH, Koo TH, Jang HO, Yun I, Kim KW, Kwon YG, Yoo MA, Bae MK: Visfatin enhances ICAM-1 and VCAM-1 expression through ROS-dependent NF-kappaB activation in endothelial cells. Biochim Biophys Acta 2008;1783:886-895. 


\section{Cellular Physiology Cell Physiol Biochem 2019;52:1398-1411}

\begin{tabular}{ll|l} 
and Biochemistry & $\begin{array}{l}\text { DOl: 10.33594/000000098 } \\
\text { Published online: 11 May 2019 }\end{array}$ & $\begin{array}{l}\text { O } 2019 \text { The Author(s). Published by } \\
\text { Cell Physiol Biochem Press GmbH\&Co. KG }\end{array}$ \\
\cline { 2 - 3 }
\end{tabular}

Lin et al.: Visfatin Promotes Monocyte Adhesion and Its Signaling Pathway

- 14 Lee WJ, Wu CS, Lin H, Lee IT, Wu CM, Tseng JJ, Chou MM, Sheu WH: Visfatin-induced expression of inflammatory mediators in human endothelial cells through the NF- $\kappa$ B pathway. Int J Obes (Lond) 2009;33:465-472.

- 15 Liu SW, Qiao SB, Yuan JS, Liu DQ: Visfatin stimulates production of monocyte chemotactic protein-1 and interleukin-6 in human vein umbilical endothelial cells. Horm Metab Res 2009;41:281-286.

- 16 Griendling KK, Sorescu D, Ushio-Fukai M: NAD(P)H oxidase: role in cardiovascular biology and disease. Circ Res 2000;86:494-501.

- 17 Lin YT, Jian DY, Kwok CF, Ho LT, Juan CC: Visfatin promotes foam cell formation by dysregulating CD36, SRA, ABCA1, and ABCG1 expression in RAW264.7 macrophages. Shock 2016;45:460-468. 